\title{
Who cares about the digital culture at school?
}

\author{
Elisabete Cruz \\ ecruz@ie.ulisboa.pt \\ Instituto de Educação, Universidade de Lisboa, Portugal \\ Fernando Albuquerque Costa \\ fc@ie.ulisboa.pt \\ Instituto de Educação, Universidade de Lisboa, Portugal

\section{Carolina Pereira} \\ cmpereira@ie.ulisboa.pt \\ Instituto de Educação, Universidade de Lisboa, Portugal
}

\begin{abstract}
The article assumes that the expansion of cultural content in basic education implies a qualitative change in the entire curriculum system. It rescues the idea of social micro spaces of common curriculum selection and reconfiguration and underlines the role of decision-makers in different groups. Namely, experts and specialists who, within the scope of the Learning Outcomes Project launched by the Portuguese Ministry of Education, supported the legitimation of ICT as a transdisciplinary learning area, consenting to shared responsibility in promoting digital culture. Based on the study carried out, involving 11 interviews, the article reveals the reasons that justify the detachment from a social practice that, paradoxically, was desired to be more articulated, integrated, and open to digital culture.
\end{abstract}

\section{Keywords}

ICT; curriculum; digital culture; transdisciplinary learning area; basic education 


\section{Introduction}

The research on curricular integration of Information and Communication Technologies (ICT), although a big theme nowadays and object of passionate debate in schools and educational settings in the last few decades, approaching a series of fundamental questions on teaching, pedagogy, and school role for integral education of students, it does not yet account for the substantial analysis on the relation between the right to digital culture, namely the access to new technologies and the intentional development of new digital learning outcomes, and the curriculum areas that are part of the basic education and at service of a just and egalitarian society project.

It is certain that a good part of the studies and systematic analysis seeks to look closely at school context and main players in the teaching and learning processes, more specifically teachers and students. In this case, besides the focus on the pedagogical use of digital technologies to respond to the demand of the new digital culture, across or in specific curriculum areas (Southcott \& Crawford, 2011; Cassells \& Dlamini, 2019; Viberg, Grönlund, \& Andersson, 2020), some studies also provide evidence of how and why digital learning and teaching can benefit learners, teachers, and schools (Destebaşi, 2015; ICF Consulting Services, 2015; Karen, 2019).

Other lines of research stand out for the discussion and disclosure of different dilemmas, tensions and divergences, namely between learning practices that occur in schools and social practices that students develop outside the classroom (Fraillon, Ainley, Schulz, Friedman, \& Gebhardt, 2014; Jornet \& Gil, 2018; Pineida, 2011). We are equally well-warned on the enormous discrepancies and existing variations, be it on matters of technology pedagogic use or in relation to the promotion of digital skills in the school curriculum (European Commission/EACEA/Eurydice, 2019). We've also known, for more than four decades, that academic subjects and cultures have a significant effect on the use of digital technologies by teachers and students (Neil, 1999).

However, little is known about what happens in the backstage of the production of the institutionalized text-curriculum that policymakers present to society, to school, and to their ultimate recipients, teachers, and students (Pinar, Reynolds, Slattery, \& Taubman, 1995). What beliefs, values, and principles guide their decisions in processes of such great responsibility? How do they socially organize the selection, organization and presentation of the cultural content they deem necessary to ensure a general education, common to all students? And, in this process and social enterprise, how do they link and accommodate the new demands that life outside of school keeps imposing on school culture? How do they ensure the right to the digital culture that society requires?

Maybe, socially, we still haven't understood the critical role of the dynamics, interactions and disputes that occur in diverse contexts and levels of decision-making in curriculum development and, consequently, the multiple aspects that impact, not only the selection of cultural contents that in a given moment is recognized as socially useful and relevant, but also the way school, teachers and students, build learning paths to respond to what society expects from them. It is precisely within the awareness of this reality that the focus and uniqueness of this study resides. Hence, assuming the importance of the action and involvement of several protagonists in the curriculum configuration, and taking into account the power and symbolic control relations complexity of the pedagogical discourse that is produced in different instances, it is important to clarify that the problematizing intention of this study, expressed in the question entitled this article, "Who wants to know about the digital culture at school?", is due to a broader research project, focused on the study of the real viability of the right to digital culture in school institutions.

We presume that the increase of curricular components that are an integral part of basic education, in this case, through the legitimization of ICT as a cross-curriculum learning area (and as connection line with digital culture), implies a qualitative change in the entire curricular system. We assume, equally, a position that recognizes teachers' importance to operate a significant change in 
education systems, but that, at the same time, rejects the idea of teachers as the ONLY agents with the power to change school. We also discard the belief that such changes must FIRST occur in teachers' training, defended by Tom Russel, at the end of last century, in the following terms:

If genuine change is to occur in schools, then those changes may have to occur FIRST in teacher education. It is certainly not enough for teacher educators to advocate changes that they have not achieved in their own practices. I have long regretted the tendency of teacher educators, situated in universities, to criticize teachers, situated in schools, for faults that the teacher educators themselves cannot show, with evidence, that they avoid in their own classrooms. Teacher educators must lead by example, not by words. (Russell, 1999).

Despite this argument' merit, that does not leave us indifferent for several reasons, this perspective supports a systemic vision of change based on a curriculum conception that assumes the meaning assigned by Gimeno Sacristán, conceiving it as social praxis that is materialized trough dynamics that involve decisions from different social groups with very diverse perspectives, philosophies, and interests (Gimeno Sacristán, 2000).

Accordingly, we presume that the challenges to the implementation of curricular and pedagogical changes, which involve a rearrangement of the curriculum map that represents the culture desired for all students, must go beyond the tradition of uncritical pedagogical thinking and research - a tradition where there is no place to bring into question the content and goals of the experiences school offers, nor space to glimpse and relate curricular practices that occur in different contexts as if any problem, that has to do with change, innovation or pedagogical renewal, can only be solved with the adoption of an action specifically directed at the methodological aspects of teaching.

Therefore, this article fits in a broader vision of the diverse facets and "codes" that, being able to act on an implicit or explicit level, end up moulding the pedagogic practices developed in authentic classrooms, with real teachers and students. Retrieving part of the previous research that intended to know the perspective of Portuguese curriculum decision maker's different groups about the sense of openness to digital culture expressed in the Learning Outcomes Project (LOP) framework, this article presents a set of reasons that make us rethink the power and responsibility of the agents that promote curricular change and innovation.

As we'll see, those reasons, that don't escape the interests, values, and presuppositions deeply rooted in academic culture and disciplinary rationality, will be presented and discussed as five big challenges to the right to access digital culture at school, namely: concepts sharing; disciplinary commitment; time management; Knowledge specialization; and ICT expertise. Before approaching each of these challenges in more detail, the curriculum context of the study and the methodological options that support our analysis, are presented.

\section{Curriculum context}

The Learning Outcomes Project (LOP) was launched in 2010 by the Ministry of Education (ME) of the XVIII Constitutional Government of Portugal (2009-2011) and resulted in the production of a set of tools and materials to support curriculum development, involving the definition of learning outcomes for each basic education (ISCED 1 and 2) subject curriculum area, including the definition of final learning outcomes for pre-school education (ISCED 0).

The initially designed plan, for LOP, foresaw four stages of development, beginning in 2010 and ending in 2013. However, it would end up being cancelled in the coming year in consequence of the $5 \mathrm{ft}$ of June 2011 elections that lead to the constitution of the XIX Portuguese Constitutional 
Government that presented a new range of Ministries and Ministers. This circumstance not only prevented the production of curriculum materials and tools foreseen to include the upper secondary education (ISCED 3) in order to cover the whole period of Portuguese compulsory schooling, it also barred the implementation of the planned schools and teachers monitoring and support system for the use of the curriculum materials produce.

Designed and developed within the framework of an educational policy that aspired the consolidation of the educational curricular organization, "introducing, without unnecessary disruptions, improvements and enhancements in the organization of the curriculum and learning" (XVIII Governo Constitucional , 2009, p. 49), the LOP assumed itself as an indispensable tool for the promotion of a path of coherence, clarification and operationality of the curricular documents that guide, at the Portuguese national level, the action lines that schools and teachers must develop with pedagogical autonomy.

Based on this huge strategic aim, it was recognized the need to reorganize and give meaning to the multiplicity of norms, prescriptions and curricular guidelines existent in Portugal, resulting from the introduction of a series of "curricular changes and innovations: new school subject, nondisciplinary curriculum areas, some new or renewed programs" (MEC-DGE, 2012). The strategy to respond to this challenge consisted in establishing parameters that defined precisely and staggered the learning goals for each level of education and each school subject or non-disciplinary curriculum area.

Apart from the reasons that, from a political point of view, seem to be more directly associated with the demand for rationalization, efficiency, and efficacy (Cruz \& Costa, 2011), the curricular conception based on learning outcomes - and supported by "results of national and international research on standards of effectiveness in curriculum development" (Alçada, 2012) - didn't intend to break up with the competency-based curriculum approach introduced in 2001 in the Portuguese Curricular Reorganization of Basic Education context. As the actors responsible for the LOP explained, the learning outcomes reflect the subject-specific competencies (knowledge, abilities, and attitudes) expected to be achieved by students in each school subject and non-disciplinary curriculum area, as well as the transversal competencies advocated in the formal curriculum (Milheiro, 2011).

As expected, the LOP started at the beginning of January 2010 and focused on the elaboration of learning outcomes for the first years of schooling (ISCED levels 0, 1, and 2). A Central Team was established for this task, led by the Instituto de Educação da Universidade de Lisboa, along with nine Experts Teams composed by subject and didactic specialists from the various school subjects and transversal learning areas, such as ICT, coordinated by higher education teachers.

As can be read on the project's website, the work of the Experts Teams resulted in a set of nine provisional curriculum frameworks - Learning Outcomes -, corresponding to each one of the school subject and non-disciplinary curriculum areas. These curriculum documents were sent to professional associations of teachers and scientific societies to collect opinions and suggestions. After analysing the received contributions, final digital versions of the Learning Outcomes were elaborated and published, in October 2010, on the education portal created specifically for the public dissemination of these documents (MEC-DGE, 2012). Later, some examples of teaching and evaluation strategies for each subject area were also elaborated and made available intending to help teachers to put curriculum frameworks of learning outcomes into action.

Concerning the development process of the ICT Learning Outcomes framework, as documented in the book entitled "Rethinking ICT in education. The teacher as transformative agent" (Costa, Rodriguez, Cruz, \& Fradão, 2012), the ICT Experts Team decided not to restrict this curriculum document to the context of the ICT subject, at the time only present in the last year of schooling in 
basic education (9th year). The core idea, as the coordinator of the ICT Experts Team clarified, was to assume ICT as a transdisciplinary curriculum area, "putting into perspective, not the teaching of technology, but learning with technology" (Costa, 2010, p.934).

Based on this rationale, the operationalization of the ICT learning outcomes followed an "integrative approach" in close articulation with the other subject areas, both from a horizontal point of view, as well as in terms of sequence and progression through basic education, including the period regarding pre-school education (Costa, Cruz, \& Fradão, 2012). Thus, in practical terms, the ICT Learning Outcomes framework was organized around four competence areas that go beyond the borders of the school subjects and allowed a greater scope of action, namely:

- Information - Ability to search and process information in line with specific goals: research, selection, analysis and summary of the data.

- Communication - Ability to communicate, interact and collaborate using network communication tools and environments as an individual learning strategy and to contribute to the learning of others.

- Production - Ability to systematize knowledge based on work processes that use the digital resources available and develop innovative products and practices.

- Security - Ability to use digital resources in compliance with security regulations (Costa, Cruz, \& Fradão, 2012, p. 6152).

To conclude this section dedicated to explaining the curricular context of the study presented here, it is important to remark that all curriculum materials produced within the LOP scope, including the ICT Learning Outcomes framework, did not assume a prescriptive nature. On the contrary, these curriculum references were made available for voluntary adoption and use by schools and teachers.

\section{Research scope and methodology}

Part of the work that we developed within the scope of a broader qualitative research project aimed, as already mentioned in the Introduction, intended to know the perspective of Portuguese curriculum decision maker's different groups about the sense of openness to digital culture expressed in the Learning Outcomes Project (LOP) framework. To achieve this goal, we selected and invited fourteen (14) curriculum experts, from an absolute universe of sixty-one (61) specialists, to an interview.

The invitation to participate in the study was made by email. In most cases, this message was preceded by an informal contact carried out personally, or through a phone call. Following the ethical guidelines and requirements in conducting educational research, the invitation text clarified the purpose of the study and assured anonymity in the treatment of the information collected. Of the 14 specialists invited, three declined the invite, one of them explicitly, yet cordially, and the other two through implicit refusal (absence of an answer to the request or by the postponing of possible involvement). Hence, we counted with the participation of eleven (11) curriculum specialists that integrated the different Experts Teams formed in the LOP, according to the distribution presented in table 1. 


\begin{tabular}{rcc}
\hline & \multicolumn{2}{c}{ Curriculum Specialists } \\
\cline { 2 - 3 } & LOP $(\mathrm{n})$ & Interviewed $(\mathrm{n})$ \\
$\mathrm{M}$ (Mathematics) & 8 & 1 \\
$\mathrm{SL}$ (Sciences) & 5 & 1 \\
$\mathrm{FL}$ (Foreign Languages) & 4 & 1 \\
H (History) & 7 & 1 \\
G (Geography) & 6 & 1 \\
AE (Artistic Expressions) & 9 & 1 \\
PE (Physical Education) & 4 & 2 \\
ICT (Information and Communication Technologies) & 6 & 1 \\
CT (Central Team) & 7 & 1 \\
\hline Total (n) & $\mathbf{6 1}$ & $\mathbf{1 1}$ \\
\hline
\end{tabular}

Table 1. Distribution of interviewed specialists $(n=11)$

Source: Own elaboration based on the data obtained in the study.

Most of the experts interviewed were female (64\%) and all had academic background in the area of education, with $64 \%$ having completed a doctorate between 1990 and 2001 . Almost all, at the time of the interview, were higher education professors $(91 \%)$, members of Professional Associations and/or Scientific Societies ( $91 \%)$ and had previous experience in producing curriculum documents like syllabus, school textbooks, and teaching support leaflets. Virtually all participants had already developed analysis and reflections, more or less in-depth, on the ICT curriculum integration (91\%). Four curriculum experts interviewed even had experience in participating in ICT national programs and government initiatives focused on the introduction of technologies in schools, which had an enormous impact on Portuguese society, such as the MINERVA Project (1985-1994) and the Internet@EB1 Program (2002-2005).

The process of collecting (and analysing) data through individual interviews took place over six months, between November 2011 and May 2012, and was based on the grounded theory method (Glaser \& Strauss, 2006; Strauss \& Corbin, 1998). In practical terms, the adoption of this method resulted in the articulation of the data collection and data analysis phases (traditionally separated), and in the construction of analytic ideas based on categories and subcategories emergent from the data collected.

Taking advantage of the features of the program Weft QDA (Qualitative Data Analysis), the content analysis of the interviews began right after the first interview was made and maintained itself until the end, in a process of constant iteration aimed at refining and strengthening the data interpretation. As advocated by the grounded theory, this process started with the "open coding", a technique defined by Strauss and Corbin (1998) as "The analytic process through which concepts are identified and their properties and dimensions are discovered in data" (p. 101). The next step, although not necessarily sequential, and according to the grounded theory framework, corresponded to the "axial coding", that consisted in the differentiation and grouping of the first codes according to a semantic criterion (meaning).

This process resulted in an emerging data categorization matrix that was submitted to the appreciation of two judges who accompanied the research project as scientific advisors. After the matrix validation process, we proceeded with the organization and systematization of results, and a 
preliminary version was sent by email to each of the curriculum specialists interviewed. This document was accompanied by a message encouraging the sharing of their opinion on the analysis carried out. Only three participants responded to our request, sharing not only their impressions about the content of the text sent to them but also leaving some suggestions that were taken into consideration during the final text writing and review.

\section{Results and analysis}

Globally, the results obtained in this study, revealed that the ICT Learning Outcomes framework fell far short of materializing into a learning area under the responsibility of all school subjects - a fact that did not appear to be a great novelty, especially if we take into account that the results of a study previously carried out, focusing on the analysis of the examples of teaching and assessment strategies produced in the scope of the LOP, revealed very weak curricular connections between ICT and the various school subjects (Cruz \& Costa, 2012).

Therefore, to better understand the reasons that justify the detachment from a social practice that, theoretically, was desired to be more articulated, integrated and open to the curricular philosophy proposed in the area of ICT, this article relies on a corpus constituted by 201 Recording Units (UR), extracted from the 11 specialists' individual interviews who participated in the LOP.

From an analytical point of view, these reasons are presented and discussed below as challenges to the integration of digital culture in school. As systematized in table 2, this study found five categories of challenges, namely: a) concepts sharing; b) disciplinary commitment; c) time management; d) Knowledge specialization; and e) ICT expertise. In the following sections we describe these five categories with great detail, discussing each one under the precepts of grounded theory.

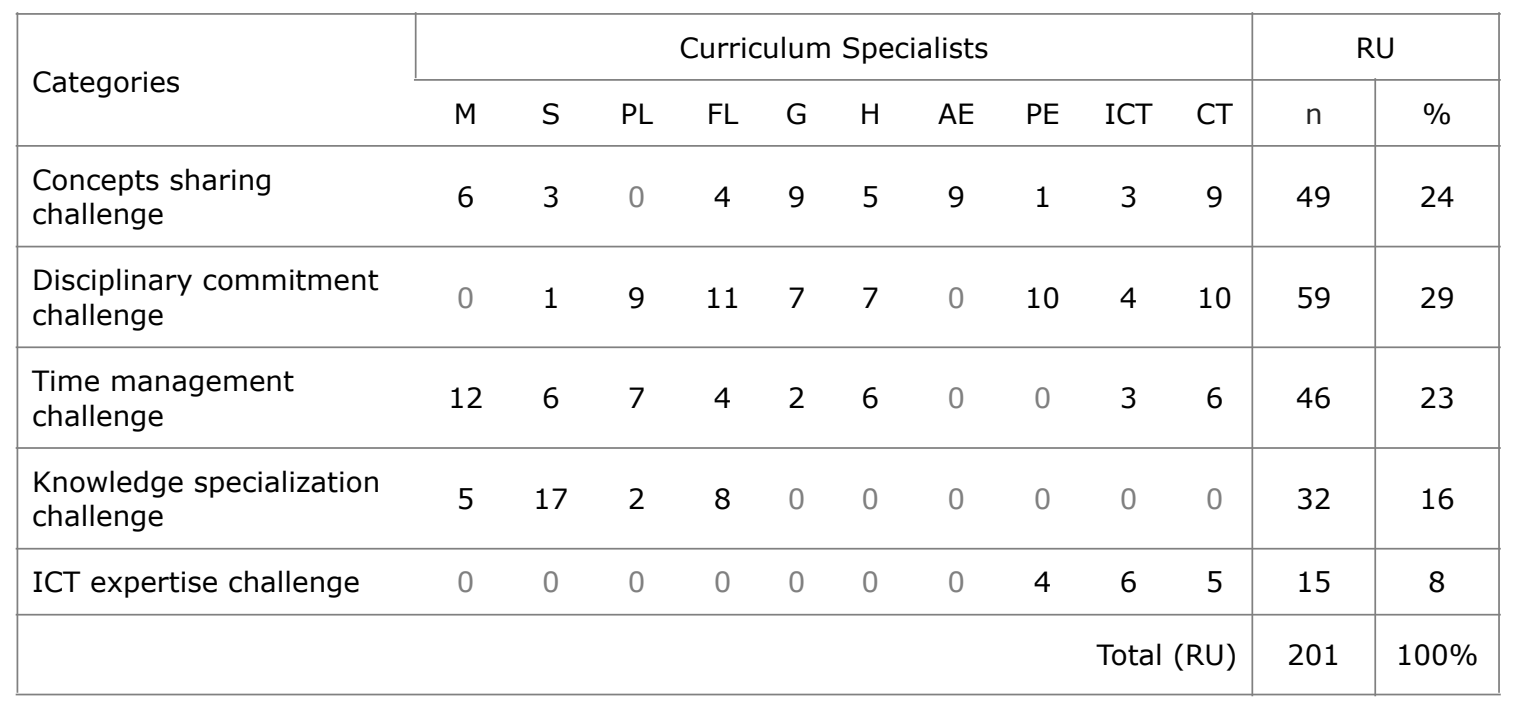

M (Mathematics); S (Sciences); PL (Portuguese Language); FL (Foreign Languages); G (Geography); H (History); AE (Artistic Expressions); PE (Physical Education); ICT (Information and Communication Technologies); CT (Central Team)

Table 2. Distribution of coded Recording Units $(n=201 \mathrm{RU})$

Source: Own elaboration based on the data obtained in the study. 


\section{a. Concepts sharing challenge}

The challenge of sharing concepts, although it is not the challenges category that accumulated more registration units, was undoubtedly the one that was most expressive in the set of specialists' representations, with almost all interviewees referring to it ( $M, S, F L, G, H, A E, P E, I C T, C T$ ). The references that are part of this category show, first of all, that the various efforts made by the Central Team to promote an articulation between the various experts' teams (representative of each school subjects), despite being highly valued, do not seem to have been effective for favouring the development of a common objectives and concepts line of curricular thinking (and practice). And, interestingly, this finding is not just about the issue of ICT curriculum integration.

In practice, the decisions taken and operationalized in the curriculum documents, produced in the scope of the LOP, reflect the understanding, values, and particular interests of each team, as recognized by some of the experts. In the wake of the difficulties faced during the construction of a common and shared language, three particularities, that according to curriculum experts, seem to have limited the harmony of thought, stand out: i) fear of creating conflicts and hurting susceptibilities, ii) difficulty in going beyond the personal opinion during general meetings, and iii) lack of communication and harmony between members of the same team.

These circumstances reveal that the desire to articulate and connect the diverse and multiple interests were betrayed by difficulties that have emerged in terms of communication, not only at the interdisciplinary level but also within the disciplinary teams themselves. As the interviewed acknowledged, this type of difficulties would come to be reflected in a very special way in the process of appropriation and operationalization of the ICT learning outcomes framework in each curricular area.

In reality, although the Central Team promoted a specific time to study, analyse and discuss various possibilities for ICT curriculum integration, and despite the decision to reinforce the transversal character of ICT (assuming a vision of shared responsibility in their learning outcomes development), and the expectations of collaboration for the production of integrated ICT teaching strategies examples (in the different school subjects), the curriculum experts recognized that the desired "transversal or transdisciplinary dialogue" was very scarce, qualifying the quality of the relationship and dynamics between different school subjects teams and the ICT as "little achieved" and "very incipient".

Considering all circumstances above, we can conclude that the sharing concepts challenge demands special care with social communication, which is, as one of the exerts clarifies, an obligation of all those who participate in this type of project, requiring from all a personal effort to "learn to communicate with others, and learn to listen, and perhaps to learn to discard some preconceived ideas that we have".

\section{b. Disciplinary commitment challenge}

The challenge to disciplinary commitment was configured as another important category of challenges for the development of curriculum documents in a shared construction approach, emerging, within the scope of this study, in the statements produced by eight of the eleven curriculum specialists ( $\mathrm{S}, \mathrm{PL}, \mathrm{FL}, \mathrm{G}, \mathrm{H}, \mathrm{PE}, \mathrm{ICT}, \mathrm{CT}$ ). In other words, almost all the interviewees, when encouraged to reflect on the reasons that could explain the difficulty in establishing more fruitful connections between the different teams and, in particular, with the ICT team, raised a set of issues that reveal an action framework that tends to move away, albeit unconsciously, from the possibilities of desired ICT curricular integration. 
Among the pieces of evidence that support this finding, we highlight the references to the fear of leading a school subject to lose its "disciplinary identity", and those that announce the character of "extreme individualism", which is, according to some interviewees, inherent to the curriculum development process at all levels of curriculum decision. Focusing our attention on the practices of constructing the curriculum-text that reaches schools to be implemented by teachers, as one of the experts points out, even in an interdisciplinary curriculum, like Artistic Expressions, each specialist "puts his foot there and always thinks that his curricular component is more important than the others. Even when history is integrated with geography or science, each one is for himself!"

These observations, which, in essence, highlight the conflict dynamics historically present in curriculum decision processes, also reveal that curriculum experts seek to preserve the "purity" of their area of expertise, defending and strengthening disciplinary boundaries in the organization of school knowledge. In addition, as noted by one of the experts, we cannot ignore the focus and permanence of the disciplinary approach in the production of all curricular documents produced within the scope of the LOP, conditioning the curriculum decision-making process. This condition, imposed administratively by the Ministry of Education, made each experts team adopt a curriculum development approach very focused on "specific competencies to which they were directly linked".

However, it should be noted that the main obstacle to the formulation of a curriculum that strengthens the ICT cross-curricular approach seems to begin with the personal difficulty to overcome the dominant ideologies and to envision other ways of organizing and giving meaning to learning. Possibly, as one respondent thinks, this is because "we are not yet in a situation of undressing [from our previous ideas to] have a problem that will mobilize the disciplines around it". So, one of the most important requirements for ICT to achieve the status of "transdisciplinary learning area" will necessarily implicate a rupture with the "curriculum tradition of extreme individualism".

\section{c. Time management challenge}

The challenge concerning time management is another part of the mosaic that we can glimpse in terms of summons to the development of social practices that aim at the establishment of curricular integration codes, namely in the context of the curriculum-text production. In this case, as suggested by most interviewees $(\mathrm{M}, \mathrm{S}, \mathrm{PL}, \mathrm{FL}, \mathrm{G}, \mathrm{H}, \mathrm{ICT}, \mathrm{CE})$, it is important to consider logistical issues associated with the problem of time (in)compatibility for establishing closer social ties, based on real work-sharing.

First of all, the fact that the coordinators of the various experts' teams are "people who were very busy" and not available to be at all times in meetings promoted by the Central Team ended up limiting the development of more articulated work. As one of the interviewees states, "the participants could not be in the meetings all the time, they could not be in the morning and the afternoon... whoever was from Lisbon [the place where the meetings took place] said very easily: $<$ I can only be in the morning or I can only be in the afternoon>".

This circumstance, as we could understand, resulted in "breaks and leaps of information" about various aspects inherent to the development of the LOP. Concerning the ICT curricular integration, it extended the gap so that each experts team could make its interpretation, without a real articulation with the ICT team. In addition, the time (in)compatibility to "work together" was also very explicitly expressed in references that reveal the plurality of rhythms and trajectories experienced by the diverse and distinct groups of experts. As one of the interviewees explains, the different experts' teams worked "at somewhat different times ... some groups were moving forward soon and others not so much". 
Still following the understanding outlined by the experts interviewed, the possibility of investing in deeper reflection processes, namely on the idea of ICT as a transdisciplinary area, was nothing more than a mirage. Beyond the lack of personal time to read all the documentation produced and shared throughout the LOP, there was also no time for truly interdisciplinary dialogues. This huge deficit of time for an enterprise that demanded a more articulated work between the various teams, emerges as a powerful impediment to the productive and effective communication between participants and, consequently, to the deepening of the social relations necessary to minimize the character of "extreme individualism" that marked the development of the LOP.

Thus, it will be inevitable to recognize that one of the great challenges facing curricular articulation practices will be to face time as a precious and necessary asset, not compatible and not subordinated to the logic and urgencies of academic and political times.

\section{d. Knowledge specialization challenge}

The challenge of specialization of knowledge also emerged, in this study context, as a relevant summon to the construction of curriculum documents that aim to support the development of pedagogical practices towards the curricular integration of ICT as a transdisciplinary area. From an analytical point of view, as can be seen in Table 2, this category of challenges resulted from the aggregation of $16 \%$ of the total recording units, present in the interviews of four specialists $(S, M$, $\mathrm{PL}, \mathrm{FL}$ ). These references show a set of cognitive and behavioural constraints, exposing the interviewed specialists' difficulties with dealing with knowledge from areas that do not fall within the scope of their specializations.

A good part of these limitations appears explicitly linked to feelings of embarrassment that seem to permeate the interpersonal relationships that are established in the academic world, making it difficult to develop discussions that imply leaving the comfort zone of each subject. In other words, as stated by one of the interviewees, the desired interdisciplinary dialogues were also severely affected by "the shame that an academic has in talking about an area that he does not know or that is not part of his specialty". It should be noted that this kind of "academic shame", which does not authorize intrusions in "foreign territories", also seems to take the form of a generalized academic commitment, which finds its basis in the fear of making mistakes. According to the interviewees' words, "everyone thinks they should not enter an area that is not theirs because the probability of saying something wrong is really big".

Other limitations associated with the challenge of knowledge specialization, expressed quite explicitly a certain personal inability to understand and mobilize knowledge considered from outside territories ("thinking that I was not able to understand [and] to deal with the knowledge of others scientific areas"). All these characteristics and circumstances, which seem to derive from certain discriminatory attitudes and behaviours that permeate the social and academic environment for the curriculum production setting, also ended up prevailing in the treatment of a theme that naturally could (or should?) interest all teams of experts. Imposing itself in the form of academic commitments and prejudices that, consciously or unconsciously, resulted in the belief that, as the interviewees think, "it is almost impossible to put people with completely different backgrounds to think in the same way."

Thus, bearing in mind that the demand to curricular integration does not require the homogeneity of all curriculum areas, on the contrary, these pieces of evidence signal the need to overcome the fear of making mistakes, overcome the limits of specialization and think about new school knowledge organization models, oriented towards improving learning processes and results. 


\section{e. ICT expertise challenge}

The challenge of the ICT expertise, although less expressive in the group of the considerations woven by the specialists (only three of the eleven interviewees explicitly mentioned this subject $(P E$, ICT, CT)), integrates a set of indicators that questions the agents responsible for the construction of the various documents of the curriculum training and the knowledge on ICT. As the interviewees suggested, one of the major problems that arose with the cross-curricular ICT approach was because "the coordinators of the various teams of specialists themselves did not immediately see the usefulness of technologies in their discipline."

As the interviewees also reminded us, an imperative for creating a proposal consistent with the curricular philosophy present in the ICT Learning Outcomes framework implies a level of in-depth knowledge about the pedagogical potential of digital technologies and their role in mediating processes of learning. That is, "to understand what [technologies] can do, how they can be used, what ways they can be integrated and related to the learning aimed at each curriculum subject." Besides the necessary knowledge, this also requires some practical experience in the didactic use of digital technologies in the teaching and learning processes. Hence, the problem, as one of the interviewees emphasizes, "is that most teachers, and I am talking about the curriculum specialists at various levels, do not yet feel ICT as a didactic work tool."

Another relevant problem that has certainly weakened the ICT cross-curricular approach is due to the very limited ICT vision, seeing it only as a tool and not as a learning area, with its own set of transversal competencies to be developed throughout schooling, in all curriculum subjects. Therefore, it is essential to understand that ICT is also a curricular area that includes a set of learning outcomes to be acquired at school.

In summary, the ICT expertise challenge reinforces the need to shift from traditional approaches, which tend to focus on the use of technologies for teaching, towards a vision that is solidly sustained and committed to improving learning in all school subjects and non-disciplinary curriculum area.

\section{Conclusions}

Considering the profusion of curricular guidelines enforced at the time the Learning Outcomes Project was launched, and that prevail nowadays, we'll have, first of all, to recognize the importance of their strategic intentionality, particularly concerning the purpose of helping teachers and schools to build a coherent and articulated curricular view from the dispersed and multiple curriculum documents (MEC-DGE, 2012).

In this scenario of curricular reconfiguration and innovation, it is also important to remark the high involvement of various agents and decision-makers in shaping the national curriculum. As noted by the National Council of Education of Portugal, "it was the first time that the Ministry [of Education] delivered the conception, organization, and coordination of a political measure of this scope to a university (Conselho Nacional de Educação, 2011, p. 63). It is also important to note the opportunity, also for the first time in our country, to consider the curricular integration of ICT in a holistic and integrative approach for the three sequential cycles of basic education (corresponding to ISCED 1 and 2), as well as for pre-school education (ISCED 0) (Costa, 2010).

This social enterprise represents a substantial step towards the identification of a 21st century ICT Profile for all Portuguese citizens, assuming a political and curricular commitment to the development of digital culture at school, however this study reveals that curriculum experts, considered here as representatives of the various school subjects and non-disciplinary areas, do 
not seem flexible enough to assume the commitment to develop ICT transversal competencies. Although at the intentions level experts recognize that the mandate of the contemporary school implies the right to digital culture, the openness found in each expert's team to accept this right, as we have seen, did not correspond exactly to an open space to integrate the "non-disciplinary" approach.

Considering the most significant features of a social practice that, in different ways, offered resistance to legitimizing ICT as a transdisciplinary learning area, we discovered and characterized five challenges to face to create more fruitful relationships between ICT and the different school subjects and, consequently, to promote intentional and coherent responses to embrace digital culture at school. Being more aware of these challenges that, as we have seen, don't escape the interests, values, and presuppositions deeply rooted in academic culture and disciplinary rationality.

\section{Acknowledgments}

The research presented in this article is made possible by a grant by the Fundação para a Ciência e a Tecnologia (FCT), grant number SFRH/BD/68461/2010.

\section{References}

Alçada, I. (2012). Metas de aprendizagem. (Ministério da Educação e Ciência (MEC) - Direcção-Geral de Educação (DGE). Retrieved from http://metasdeaprendizagem.dge.mec.pt/ metasdeaprendizagem.dge.mec.pt/index.html.

Cassells, L., \& Dlamini, N. N. (2019). Educating digital citizens through curricular incorporation: a South African solution to information poverty. International Journal of Information and Communication Technology Education, 15(3), 11-29.

Conselho Nacional de Educação. (2011). Parecer n.०2/2011 - Parecer sobre Metas de Aprendizagem. Em Diário da República, 2.a série, N.o 1, 3 de janeiro (pp. 62-65.

Costa, F. (2010). Metas de Aprendizagem na área das TIC: Aprender Com Tecnologias. Actas do I Encontro Internacional de TIC e Educação. Inovação Curricular com TIC (pp. 931-936). Lisboa: Instituto de Educação da Universidade de Lisboa.

Costa, F., Cruz, E., \& Fradão, S. (2012). ICT Curriculum Integration in the Context of the Learning Outcomes in Portugal. Proceedings of INTED2012 Conference, (pp. 6150-6159). Valencia, Spain.

Costa, F., Rodriguez, C., Cruz, E., \& Fradão, S. (2012). Repensar as TIC na educação. O professor com agente transformador ( $1^{\mathrm{a}}$ ed.). Carnaxide: Santillana.

Cruz, E., \& Costa, F. (2011). Metas de aprendizagem na área das TIC: desafios, oportunidades e implicações para o desenvolvimento curricular. Libro de Actas do XI Congreso Internacional Galego-Portugués de Psicopedagoxía (pp. 1585-1596). Coruña: Universidade da Coruña.

Cruz, E., \& Costa, F. (2012). Contributos para o estudo das TIC como área de formação transdisciplinar. II Congresso Intencional TIC e Educação. Em Direção à Educação 2.0 (pp. 1384-1401). Lisboa: Instituto de Educação da Universidade de Lisboa.

Destebaşi, F. (2015). A literature review: the impacts of digital tools on the process of teaching and learning in middle school language arts classes. Erzincan Üniversitesi Sosyal Bilimler Enstitüsü Dergisi , ÖS(II), 107-122.

European Commission/EACEA/Eurydice. (2019). Digital Education at School in Europe. Eurydice Report. Luxembourg: Publications Office of the European Union. 
Fraillon, J., Ainley, J., Schulz, W., Friedman, T., \& Gebhardt, E. (2014). Students' Use of and Engagement with ICT at Home and School. In J. Fraillon, J. Ainley, W. Schulz, T. Friedman, \& E. Gebhardt, Preparing for Life in a Digital Age. The IEA International Computer and Information Literacy Study International Report (pp. 125-164). International Association for the Evaluation of Educational Achievement. DOI 10.1007/978-3-319-14222-7.

Gimeno Sacristán, J. (2000). O currículo: uma reflexão sobre a prática (3a ed.). Trad. Ernani F. da Fonseca Rosa. Porto Alegre, Brasil: ArtMed.

Glaser, B., \& Strauss, A. (2006). The Discovery of Grounded Theory. Strategies for Qualitative Research. New Brunswick (U.S.A.) and London (U.K.): Aldine Transaction.

ICF Consulting Services. (2015). Literature Review on the Impact of Digital Technology on Learning and Teaching. Edinburgh: Scottish Government. ISBN: 978-1-78544-821-8 (web only).

Jonet, A. G. \& Erstad, O. (2018). From learning contexts to learning lives: Studying learning (dis)continuities from the perspective of the learners. Digital Education Review, 33 (June 2018), 1-25.

Karen, G. (2019) Understanding primary teachers' professional learning and practice: an activity theory lens, Journal of Curriculum Studies, 51:3, 362-383, DOI: 10.1080/00220272.2018.1488997

MEC-DGE. (2012). Apresentação . (Ministério da Educação e Ciência (MEC) - Direcção-Geral de Educação (DGE). Retrieved from http://metasdeaprendizagem.dge.mec.pt/metasdeaprendizagem.dge.mec.pt/ sobre-o-projecto/apresentacao/index.html.

Milheiro, A. R. (2011). Avaliação das aprendizagens no âmbito do Projecto Metas de Aprendizagem. Relatório de estágio de mestrado, Ciências da Educação (Avaliação em Educação). Lisboa, Portugal: Universidade de Lisboa, Instituto de Educação.

Neil, S. (1999). Differences in educational computer use: the influence of subject cultures. Curriculum Journal, $10(1), 29-48$.

Pinar, W., Reynolds, W., Slattery, P., \& Taubman, P. (1995). Chapter 13: Understanding Curriculum as Institutionalized Text. Counterpoints, 17, 661-791. Retrieved from http://www.jstor.org/stable/ 42974929.

Pineida, F. O. (2011). Competencies for the 21st Century: Integrating ICT to Life, School and Economical Development. Procedia - Social and Behavioral Sciences, 28(2011), 54-57. Doi:10.1016/ j.sbspro.2011.11.011.

Russell, T. (1999). The challenge of change in (teacher) education. The Challenge of Change in Education Conference. Sydney: University of Technology.

Southcott, J., \& Crawford, R. (2011). The Intersections of Curriculum Development: Music, ICT and Australian Music Education. Australasian Journal of Educational Technology, 27(1), 122-136.

Strauss, A., \& Corbin, J. (1998). Basics of Qualitative Research: Techniques and Procedures for Developing Grounded Theory. Thousand Oaks, California: Sage Publications, Inc.

Viberg, O., Grönlund, §., \& Andersson, A. (2020). Integrating digital technology in mathematics education: a Swedish case study. Interactive Learning Environments, 1-12. DOI: 10.1080/10494820.2020.1770801.

XVIII Governo Constitucional (2009). Programa do XVIII Governo Constitucional (2009-2013). Portugal. 